\title{
Electrocardiographic Abnormalities in Neurological Diseases
}

\author{
Rui Póvoa, Luciano Cavichio, Ana Lúcia de Almeida, Danielle Viotti, Celso Ferreira, \\ Luciane Galvão, João Pimenta
}

São Paulo, SP - Brazil

\begin{abstract}
Objective - To evaluate electrocardiographic abnormalities in patients with neurologic diseases.

Methods - We studied 161 patients with neurologic disorders by analyzing the 12-lead electrocardiogram during the pathological process. An expert who did not know anything about the patients evaluated the traces.
\end{abstract}

Results - Neurological process included brain tumor (41\%), stroke (27.3\%), cerebral aneurysm (15.5\%), subarachnoid hemorrhage (6.8\%), subdural hemorrhage (5\%), and head injury (4.4\%). Electrocardiograms were normal in $61 \%$ of cases, and the most frequent abnormality was ventricular repolarization (23.7\%). The presence of T waves (4.6\%) and prolonged QT intervals (8.8\%) was the most characteristic of brain injuries.

Conclusion - We observed a lower incidence of electrocardiographic abnormalities than that described in the literature.

Key words: electrocardiography, neurologic diseases, QT interval
Hospital do Servidor Público Estadual.

Mailing address: João Pimenta - Rua das Camélias, 357 - 04048-060 - São Paulo, SP - Brazil - E-mail: pimenta@cardiol.br
Central nervous system disorders are known to be responsible for the onset of cardiac alterations, frequently observed in the electrocardiogram ${ }^{1,2}$. Although serum potassium disturbance has been suggested as an important factor in these alterations, this finding was not confirmed in several studies ${ }^{3,4}$. The majority of studies suggest that these ECG abnormalities result from disturbances in the autonomous system, due to neurologic disease, promoting a local excess of catecholamines, associated with enhanced adrenal production, and activation of the calcium channels, leading to an increase in cytosolic and mitochondrial calcium, as well as release of free radicals, causing contraction band necrosis and reflected in ECG alterations. Although the causes of cardiac alterations are a matter of scientific speculation, evidence exists that myocardial lesion is mediated by catecholamines, and an important left ventricle dysfunction with the liberation of cardiac enzymes, such as troponin-I, occurs in some cases ${ }^{5}$. The increase in intracranial pressure is also considered a factor in these alterations ${ }^{6}$.

Data described by Goldstein ${ }^{7}$ in a certain population demonstrated a high incidence (up to 92\%) of electrocardiogram alteration in neurological disorders. This result was not observed in clinical practice. In our study, we observed a frequency of electrocardiogram alterations in pathological brain processes contrary to that observed in the literature.

\section{Methods}

We carried out a study for 6 years of 1,590 patients admitted because of neurological diseases, such as brain tumor, stroke, subarachnoid hemorrhage, subdural hemorrhage, brain aneurysm, and head injury, with ages ranging from 10 to 60 years. Patients with concomitant diseases that could lead to electrocardiogram alterations, such as systemic hypertension, cardiac valve abnormalities, coronary diseases, congenital cardiopathies, endocrine diseases, and others were excluded. Those patients who did not have a complete clinical history or an electrocardiogram performed at the time of admittance were also excluded. A cardiologist unaware of the neurological diseases and any other clinical data regarding the patient interpreted the elec- 
trocardiograms. In electrocardiogram evaluation rhythm, QRS complex, T wave, ST segment, PR interval, QT interval corrected using Bazett's formula and the presence of bundle branch blocks or fascicular blocks were analyzed.

\section{Results}

We evaluated 1590 charts, and 1,429 were excluded because they did not meet inclusion criteria. We included 161 patients, 87 women $(54 \%)$ with a mean age of 43.8 years. Neurological diseases found included 66 cases $(41 \%)$ of brain tumor, 44 cases $(27.3 \%)$ of stroke, 25 cases $(15.5 \%)$ of brain aneurysm, 11 cases $(6.8 \%)$ of subarachnoid hemorrhage, 8 cases $(5 \%)$ of subdural hemorrhage, and 7 cases $(4.4 \%)$ of head injury. The electrocardiograms analyzed were abnormal in 35.4\% (57/161) and normal in 104 of the remaining patients $(64.5 \%)$. Frequency of alterations of QRS complex, ST segment, and T wave in neurological diseases are found in table I, and the presence of alterations of the rhythm is found in table II. Figure 1 presents the electrocardiogram of a patient with stroke, with suggestive $\mathrm{T}$ waves (cerebral T wave), with significant increase in T wave duration, as well as ST segment and, consequently prolonged QT intervals. Figure 2 presents the electrocardiogram of a patient with subarachnoid hemorrhage, with alterations suggestive of subepicardial ischemia in the anterior wall (fig. 2-A). These alterations disappeared after proper surgical treatment (fig. 2-B).

\section{Discussion}

We noticed a discrepancy in the findings described regarding the incidence of electrocardiogram alterations in neurological diseases. Hersch ${ }^{3}$ described 20 cases, with a pattern of subepicardial ischemia in $15 \%$ and ST segment elevation in $8 \%$ of the patients, without prolonged QT interval. In the present study, we verified in the 66 cases of brain tumor, a pattern of subepicardial ischemia in only $7.5 \%$ of the cases, and ST segment elevation in $3 \%$ of the cases. Goldstein ${ }^{7}$ evaluated 150 cases of patients with acute stroke and 150 controlled cases paired by sex and ages to determine the frequency of abnormalities in the electrocardiogram in the several groups, observing alterations in $92 \%$ of cases, characteristic of neurological diseases, prolonged QT interval in $45 \%$ of the cases, and cerebral T wave in $29 \%$ of cases (fig. 1). Burch et $\mathrm{al}^{8}$, in a report of 17 cases, found prolonged QT intervals in all patients and $\mathrm{U}$ wave in $64.7 \%$. In our cohort, in 44 cases of acute stroke, the incidence of abnormalities in the electrocardiogram was $29.6 \%$. The alterations considered as indicative of cerebral lesions were not frequent, considering that in all cases the cerebral $\mathrm{T}$ wave appeared in $2.5 \%$ (4/161), prolonged QT interval in $5.6 \%(9 / 161)$, and subepicardial ischemia (less specific) in $4.9 \%$ (8/161). In Goldstein's study ${ }^{7}$, an incidence of $25 \%$ of new arrhythmias was observed compared with $3 \%$ of the control group. Among these, atrial fibrillation was the most common, present in $14 \%$ of the cases, followed by ventricular arrhythmia in 5\%, with ventricular extrasystoles in the majority of cases. Although the analysis of any arrhythmic event by using only conventional electrocardiography is not accurate, atrial fibrillation occurred in $2.3 \%$ of cases and was the only arrhythmia found in this group of patients.

In the studies on subarachnoid hemorrhage, Byer et al ${ }^{9}$ assessed 29 patients, observing that $67 \%$ of the electro-

\begin{tabular}{|c|c|c|c|c|c|c|c|c|}
\hline & $\begin{array}{l}\text { Non-specific ST-T } \\
\text { abnormalities }\end{array}$ & $\begin{array}{l}\text { Subepicardiol } \\
\text { ischemia }\end{array}$ & $\begin{array}{l}\text { Subendocerdiol } \\
\text { ischemia }\end{array}$ & $\begin{array}{l}\text { Brain } \\
\text { T wave }\end{array}$ & $\begin{array}{l}\text { Prolonged } \\
\text { QT interval }\end{array}$ & $\begin{array}{c}\mathrm{U} \\
\text { wave }\end{array}$ & $\begin{array}{c}\text { Bundle } \\
\text { branch block }\end{array}$ & $\begin{array}{c}\text { ST } \\
\text { elevation }\end{array}$ \\
\hline Tumor $(n=66)$ & $16(24)$ & 0 & $6(7.5)$ & 0 & $2(3)$ & 0 & $2(3)$ & $2(3)$ \\
\hline Stroke $(n=44)$ & $6(13.5)$ & 0 & 0 & $1(2.3)$ & $3(6.8)$ & $1(2.3)$ & $3(6.8)$ & $1(2.3)$ \\
\hline Aneurysm $(n=25)$ & $6(20)$ & $2(8)$ & $1(4)$ & $1(4)$ & 0 & $1(4)$ & $1(4)$ & 0 \\
\hline SAH $(n=11)$ & $2(18.2)$ & 0 & $1(9)$ & $1(9)$ & $2(18)$ & $1(9)$ & 0 & 0 \\
\hline SDH $(n=8)$ & $3(37.5)$ & 0 & 0 & $1(12.5)$ & $2(25)$ & 0 & 0 & 0 \\
\hline Head Injury $(n=7)$ & $2(28.6)$ & 0 & $1(14.3)$ & 0 & 0 & 0 & 0 & $1(14.3)$ \\
\hline Total $(\mathrm{n}=161)$ & 35 (21.7) & $2(1.2)$ & $9(5.6)$ & $4(2.5)$ & $9(5.6)$ & $3(1.9)$ & $6(3.8)$ & $4(2.5)$ \\
\hline
\end{tabular}

\begin{tabular}{|c|c|c|c|c|c|c|c|}
\hline & $\begin{array}{c}\text { Sinus } \\
\text { bradycardia }\end{array}$ & $\begin{array}{c}\text { Sinus } \\
\text { tachycardia }\end{array}$ & $\begin{array}{c}\text { AV } \\
\text { block }\end{array}$ & $\begin{array}{c}\text { Atrial } \\
\text { fibrillation }\end{array}$ & $\begin{array}{l}\text { Supraventricular } \\
\text { ectopic beats }\end{array}$ & $\begin{array}{l}\text { Ventricular } \\
\text { ectopic beats }\end{array}$ & $\begin{array}{c}\text { Junctional } \\
\text { rhythm }\end{array}$ \\
\hline Tumor $(n=66)$ & $4(6.1)$ & 0 & $2(3)$ & 0 & $3(4.5)$ & 0 & 0 \\
\hline Stroke $(n=44)$ & 0 & 0 & 0 & $1(2.3)$ & 0 & 0 & 0 \\
\hline Aneurysm $(\mathrm{n}=25)$ & 0 & $1(4)$ & $1(4)$ & 0 & $1(4)$ & $1(4)$ & 0 \\
\hline SAH $(n=11)$ & $1(9.1)$ & 0 & $1(9.1)$ & 0 & 0 & 0 & $1(9.1)$ \\
\hline SDH $(n=8)$ & 0 & 0 & 0 & 0 & $1(12.5)$ & 0 & 0 \\
\hline Head Injury $(n=7)$ & 0 & 0 & 0 & 0 & 0 & 0 & 0 \\
\hline Total $(n=161)$ & $5(3.1)$ & $1(0.6)$ & $4(2.5)$ & $1(0.6)$ & $3(1.9)$ & $4(2.5)$ & $1(0.6)$ \\
\hline
\end{tabular}




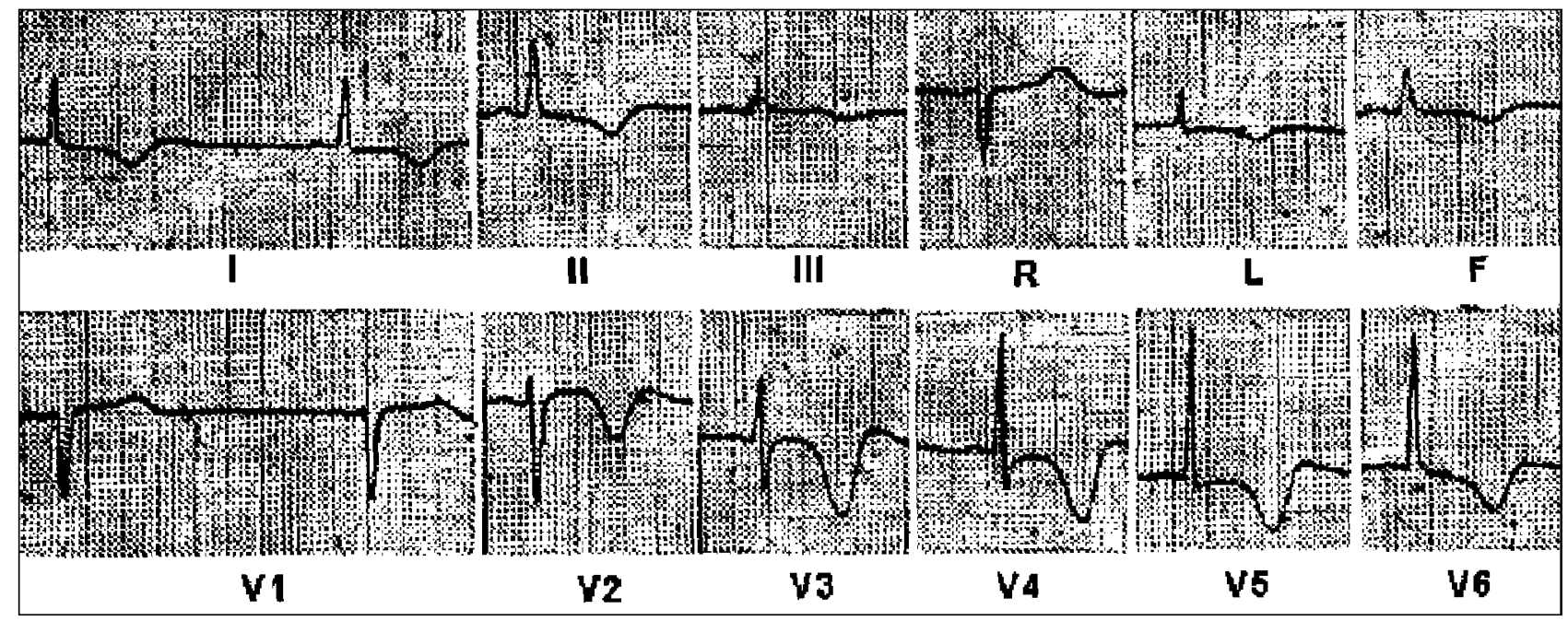

Fig. 1 - Electrocardiogram of patient with stroke. Observe sinus bradycardia, inverted T waves with wide bases (cerebral T wave), and prolonged QT interval.

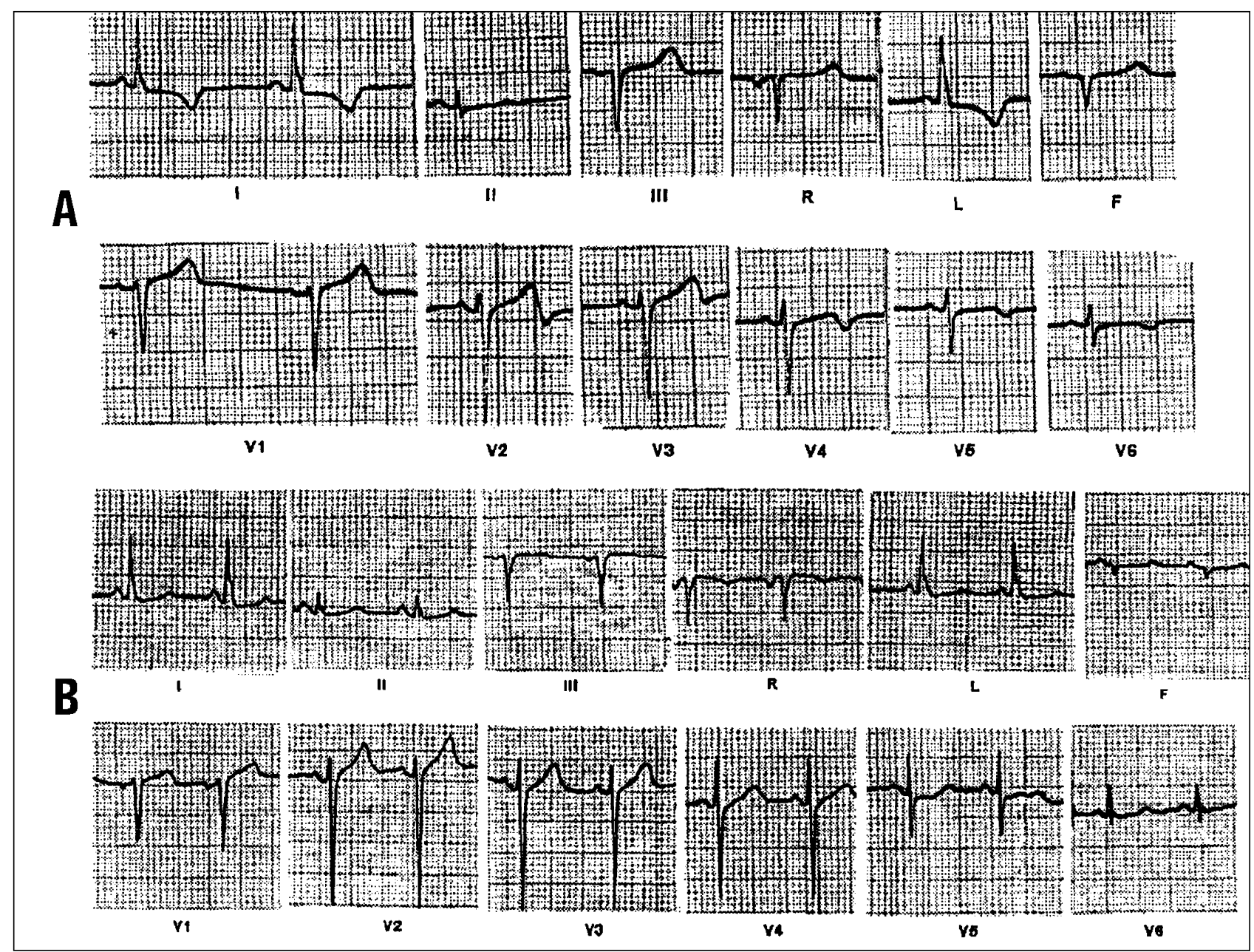

Fig. 2 - Electrocardiogram of patient with subarachnoid hemorrhage. In A, primary and diffuse alterations of T wave, suggesting myocardial ischemia. In B, after surgical therapy, electrocardiogram is normal.

cardiograms suggested a pattern of ischemia associated with a prolonged QT interval. Croop (Check the spelling of Croop. It is different in the reference list.) and Manning ${ }^{10}$ studied 28 cases, finding patterns of myocardial ischemia. Rudehill et al ${ }^{11}$, in a study of 22 patients, verified only 2 normal electrocardiograms. Among the most frequent 
abnormalities were prolonged QT intervals (75\%), prominent $U$ waves (45\%), and cerebral T waves (15\%). Brouwers et al ${ }^{12}$ also demonstrated, in a study of 61 patients, a pattern of ischemia in $50.8 \%$, $\mathrm{U}$ waves in $44.2 \%$, and prolonged QT intervals in $39.3 \%$. However, in our cohort, in the 11 cases of subarachnoid hemorrhage, only $36.4 \%$ were abnormal. Stober et al ${ }^{13}$ described sinus bradycardia in $23 \%$, multifocal ventricular ectopic beats in 54\%, asystolic intervals in $27 \%$, and atrial fibrillation in $4 \%$ of the cases with conventional electrocardiography. In the present study, sinus bradycardia, atrioventricular block, and the junctional rhythm were the only arrhythmias found ( $9.1 \%$ for each). Kantor and Krishnan ${ }^{14}$ discussed in a literature review the high incidence of alterations in electrocardiograms in cases of head injury, in contrast with $57.1 \%$ of the normal electrocardiograms reported in their cohort. Likewise, of the 8 cases of subdural hemorrhage of in the present study, $50 \%$ of the electrocardiograms were normal, and the most frequent alteration observed was the nonspecific alteration of repolarization, corresponding to $37.5 \%$ of cases.

These differences in the prevalence of electrocardiographic alterations discussed in the literature probably occurred because of the presence, in these patients, of diseases that may alter the electrocardiogram, especially hypertension, which is frequently associated with left ventricular hypertrophy. In the present study, we tried to minimize this problem, excluding patients with diseases that may lead to alterations in the electrocardiogram.

In conclusion, the findings obtained suggest that electrocardiographic alterations found in neurological disorders are frequent $(35.4 \%)$, but not as frequent as those reported in the literature, and mostly nonspecific. However, lesions characteristic of cerebral lesions (cerebral T wave, prolonged QT intervals) are not frequent.

\section{References}

1. Calvo-Romero JM, Soria-Pantoja RF, Garcia JDA, et al. Electrocardiographic abnormalities in subarachnoid hemorrage. Rev Neurol 2001; 6: 536-7.

2. Hirashima $\mathrm{Y}$, Takashima S, Matsumura N, et al. Right sylvian fissure subarachnoid hemorrage has electrocardiographic consequences. Stroke 2001; 32: 2278-81.

3. Hersch C. Electrocardiographic changes in subarachnoid hemorrhage, meningitis and intracranial space-occupying lesions. Brain Heart J 1964; 26: 785-93.

4. Wasserman F, Choquette G, Cassinelli R. The eletrocardiographic observations in patients with cerebrovascular accidents. Am J Med Sci 1956; 231: 502-10.

5. Parekh N, Venkatesh B, Cross D, et al. Cardiac troponin I predicts myocardial dysfunction in aneurysmal subarachnoid hemorrhage. J Am Coll Cardiol 2000; 36: $1328-35$

6. Levine H. Non-specificity of the electrocardiogram associated with coronary artery disease. Am J Med 1953; 15: 344

7. Goldstein DS. The electrocardiogram in stroke: relationship to pathophysiological type and comparison with prior tracings. Stroke 1979; 10: 253-9.
8. Burch GE, Meyers R, Abildskov A. A new electrocardiographic pattern observed in cerebrovascular accidents. Circulation 1954; 9: 719-23.

9. Byer E, Ashman R., Toth LA. Electrocardiogram with large upright T waves and long QT intervals. Am Heart J 1947; 33:796-806.

10. Cropp GJ, Manning G. Electrocardiographic changes simulating myocardial ischemia and infarction associated with spontaneous intracranial hemorrhage. Circulation 1960; 22: 25-38.

11. Rudehill A, Gordon E, Sylven C. A study of ECG abnormalities and myocardial specific enzymes in patient with subarachnoid hemorrhage. Acta Anaesth Scand 1982; 26: 344-50.

12. Brouwers PJ, Wijdicks EFM, Hasan D, et al.. Serial electrocardiographic recording in aneurysmal subarachnoid hemorrhage. Stroke 1989; 20:1162-7.

13. Stober T. Cardiac arrhythmias in subarachnoid hemorrhage. Acta Neurochir 1998; 93: 37-44.

14. Kantor HL, Krishman SC. Cardiac problems in patients with neurologic disease. Cardiol Clin 1995; 13: 179-208. 